connected with smoking. In the intervals between smoking an episode of reflux occurred once every $156 \cdot 6$ minutes $\left(\chi^{2}=416\right.$ with 2 D.F., $P<0.001$ ).

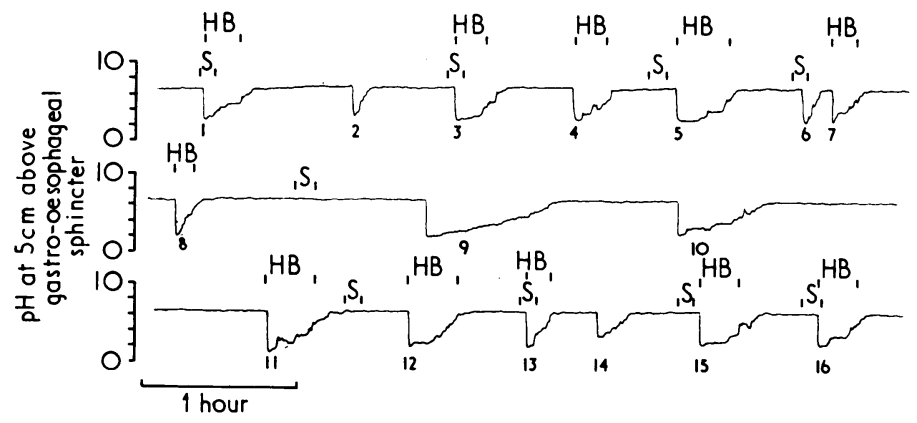

FIG. 4-Fifteen-hour recording of lower oesophageal $\mathrm{pH}$ in a 49-year-old patient. Nine cigarettes were smoked. Episodes 1, 3, 5, 6, 13, 15, and 16 occurred during or immediately after smoking. Two cigarettes were smoked without associated reflux. Heartburn occurred duirng 11 of the 16 reflux episodes. $\mathrm{HB}=$ Heartburn. $\mathrm{S}=$ Smoking.

The proportion of reflux episodes in the overnight recording which were associated with heartburn was not affected by the subject's smoking. Heartburn occurred with $68 \%$ of the smoking episodes of reflux, with $65 \%$ of the episodes after smoking, and with $56 \%$ of the non-smoking episodes $(P=0 \cdot 1)$.

The patients smoked 164 cigarettes (nearly seven each), and only 67 were smoked without associated reflux.

\section{Discussion}

The reason for the weakness of the gastro-oesophageal sphincter, which allows reflux to occur, is not known. Its anatomical situation has been thought to be crucial, though the work of Cohen and Harris (1971) casts doubt on the importance of this factor. The sphincter is under neural and hormonal control (Ellis et al., 1960; Lind et al., 1968; Castell and Harris, 1969; Giles et al., 1969; Lipshutz and Cohen, 1971) but disturbances of these can rarely be found as the cause of a patient's reflux. In the great majority of patients with symptomatic reflux no fundamental reason can be found.

Similarly, although extrinsic factors influence the tone of the sphincter (anticholinergic drugs, intragastric pressure, intra- abdominal pressure) they have not been shown to cause chronic symptomatic reflux. This paper shows that smoking a cigarette reduces the gastro-oesophageal "barrier" pressure and may allow reflux, with accompanying symptoms, to occur. The probable mechanism is that inhaled nicotine blocks the cholinergic control mechanism. In-vitro nicotine causes relaxation of circular muscle fibres from the lower oesophagus (Ellis et al., 1960; Misiewicz et al., 1969).

We have also shown that the effects on the sphincter may take place with each successive cigarette. Gastro-oesophageal reflux may occur without symptoms (Skinner, 1966), but it is likely that heartburn is the product of frequent repeated reflux episodes over a sustained period-perhaps months or years. Chronic cigarette smoking could easily be the only extra factor needed to convert occasional asymptomatic reflux into frequent, painful reflux, and the corollary that stopping smoking may reverse the process is probably true.

The manometric apparatus was generously loaned by Reckitt \& Colman Ltd., and our technical help was financed by the Wellcome Foundation. Mr. W. A. Pridmore gave us invaluable statistical advice. Carol Stanciu is the recipient of a research grant from the Leeds Regional Hospital Board.

\section{References}

Atkinson, M., Edwards, D. A. W., Honour, A. J., and Rowlands, E. N. (1957). Lancet, 2,1138

Benz, L. J., et al. (1972), Gastroenterology, 62, 1.

Castell, D. O., and Harris, L. D. (1969). Gastroenterology, 56, 124

Cohen, S., and Harris, L. D. (1971). New England fournal of Medicine, 284, 1053.

Dennish, G. W., and Castell, D. O. (1971). New England Journal of Medicine,

Ellis, F. G., Kauntze, R., and Trounce, J. R. (1960). British fournal of Surgery, 47, 466 .

Giles, G. R., Mason, M. C., Humphries, C., and Clark, C. G. (1969). Gut, 10,730 .

Haddad, J. K. (1970). Gastroenterology, 58, 175.

Lind, J. F., Crispin, J. S., and McIver, D. K. (1968). Canadian fournal of Physiology and Pharmacology, 46, 233.

Lipshutz, W., and Cohen, S. (1971). Gastroenterology, 61, 16.

Longhi, E. H., and Jordan, P. H. (1969). Surgery, Gynecology and Obstetrics, $129,734$.

Misiewicz, J. J., Waller, Sheila L., Anthony, P. P., and Gummer, J. W. P. (1969). Quarterly fournal of Medicine, 38, 17.

Pope, C. E. (1967). Gastroenterology, 52, 779.

Skinner, D. B. (1966). American fournal of Digestive Disorders, 11, 771.

Winans, C. S., and Harris, L. D. (1967). Gastroenterology, 52, 773.

\title{
Study of Chromosomes in the Newborn after Ultrasonic Fetal Heart Monitoring in Labour
}

\author{
MARY LUCAS, MARY MULLARKEY, USAMA ABDULLA
}

British Medical fournal, 1972, 3, 795-796

The effect of continuous-wave ultrasound on the chromosomes of newborn infants has been investigated. Twenty-four women were studied during labour. The fetal heart was monitored by a Sonicaid FM2 monitor applied to the abdomen, and continuous monitoring undertaken for intervals varying from

\footnotetext{
Galton Laboratory, University College, London N.W.1

MARY LUCAS, M.B., B.s., Lecturer

MARY MULLARKEY, B.sc., Technician
Institute of Obstetrics and Gynaecology, Queen Charlotte's Maternity Hospital, London W.6
USAMA ABDULLA, M.R.C.o.G. Senior Registrar (Present appointment: Lecturer, Oxford University, Nuffield Department of Obstetrics and Gynaecology, John Radcliffe Hospital, Oxford)

1 hour 5 minutes to 9 hours 25 minutes. There was no increase in the number of chromosome aberrations in cultures of blood taken from the insonated babies when compared with controls.

\section{Introduction}

The use of diagnostic ultrasound in medicine, especially in obstetrics, has increased rapidly in recent years.

Antenatal investigation of the fetus with both pulsed and continuous-wave ultrasound has been established for many year (Willocks et al., 1967; Campbell, 1968; Donald, 1968 Donald and Abdulla, 1968; Abdulla, 1971). Recently, diagnostic continuous-wave ultrasound has been introduced to monitor the fetal heart in labour. 
Types and Frequencies of Aberrations in Control and Insonated Cultures

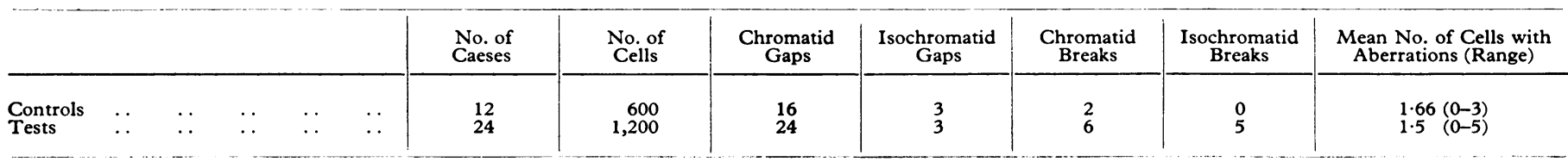

Previously we investigated the effect of an ultrasonic fetal heart monitor (Sonicaid FM2) on the maternal and fetal chromosomes in 12 women who were admitted for termination of pregnancy by hysterotomy (Abdulla et al., 1971). Since the appliance is now in use in clinical practice in Great Britain, and because of earlier reports suggesting the possibility of chromosome damage from the medical use of ultrasound (Macintosh and Davey, 1970, 1972; Serr et al., 1970), we have investigated the effect of ultrasonic fetal heart monitoring on the chromosomes of newborn infants.

\section{Methods}

Twenty-four newborn infants were chosen at random of women who had had an ultrasonic fetal heart monitor applied to their abdomen in labour. These infants constituted the insonated group. The ultrasonic transducer was applied to the maternal abdomen at the point at which maximal signal can be picked up using olive oil as a coupling medium. The transducer was applied again when the signal was lost.

The control group was made up of 12 infants chosen at random from newborn infants of mothers who had not had ultrasonic fetal heart monitoring while in labour or $x$-ray or ultrasonic examination at any stage of the pregnancy.

Ultrasonic Power Levels.-The Sonicaid FM2 produces continuous-wave ultrasound at a frequency of about $2 \mathrm{MHz}$. The ultrasonic intensity was measured by the manufacturers as $5 \mathrm{~mW} / \mathrm{cm}^{2}$ at skin level.

Cytogenetic Methods.-The method of culture used was that in routine use at the Galton laboratory. Blood specimens obtained by heel-prick were inoculated directly into the culture medium (micromethod) and transported as rapidly as possible to the laboratory. The cultures were incubated at $37^{\circ} \mathrm{C}$ for $48-54$ hours, demecolcine (Colcemid) being added for the last two hours of culture. Air-dried chromosome preparations were made after the usual hypotonic treatment and fixation in alcohol-acetic acid. The specimens were coded by being numbered consecutively, and the laboratory staff did not know whether they were from insonated or control infants. The specimens were examined by two observers, who each scored 25 well-spread mitoses for aberrations, which were defined as previously described (Abdulla et al., 1971). One cell was seen which contained two dicentric chromosomes and two fragments. No rings or chromatid interchanges were seen.

\section{Results}

The types and frequencies of aberrations found are shown in the Table together with the mean and the range of numbers of cells with an aberration per 50 cells for the control and the insonated group. No significant differences in either the numbers of cells with aberrations or the types of aberration could be detected.

\section{Discussion}

It has been shown (Buckton et al., 1967) that lymphocytes do not divide frequently, so that any damage inflicted to the chromosomes may be visible after many years; thus no attempt was made to collect blood immediately after delivery. Specimens were taken when convenient for the laboratory work. The age of the babies varied from 1 to 9 days and the mean and range of age when the specimen was taken did not differ significantly between the two groups. The infants in both groups were similar in maturity, average weight, and Apgar score at birth. The average age of the mothers of infants in both groups was also similar, the range being 17 to 35 years.

The cultures were harvested after two days so that cells could be examined in the first mitosis after insonation. This is necessary to obtain an accurate assessment of the effect of any treatment (U.N. Scientific Committee, 1969), as cells carrying complex abnormalities may be lost at the first mitosis. As the average number of cells with an aberration did not vary between the two groups the finding of one cell from an insonated infant containing two dicentric chromosomes and two acentric fragments is not thought to be of significance. Such aberrations are rarely seen in cells from subjects who have not been exposed to mutagenic agents. The frequency of dicentrics, about one in 4,000 cells, has been computed from several sets of data (Evans, 1970). In our studies of the effect of ultrasound on chromosomes a total of 5,600 cells have been examined-1,000 from controls and 2,800 from insonated patients in a previous study (Abdulla et al., 1971), and 600 from controls and 1,200 from insonated patients in the present series-so it is not surprising that one cell containing a complex chromosome aberration has been found.

These in-vivo findings when considered with recent invitro experiments (Backton and Baker, 1972; Bleaney et al., 1972; Coakley et al., 1972; Hill et al., 1972; Watts et al., 1972) indicate that diagnostic power levels of ultrasound do not cause chromosomal damage.

We thank Professor C. J. Dewhurst for his help and guidance. Also we acknowledge the help of Sonicaid Limited and the Department of Health and Social Security, who made this study possible.

Requests for reprints should be addressed to Dr. M. Lucas, Galton Laboratory, University College, London N.W.1.

\section{References}

Abdulla, U. (1971). In Ultrasonographia Medica, ed. J. Böck, and K. Ossoinig, vol. 3, p. 185, Vienna, Wiener Medizinische Academie. Abdulla, U., et al. (1971). Lancet, 2, 829.

Backton, K. E., and Baker, N. V. (1972). British fournal of Radiology, 45, 340 .

Bleaney, B. I., Blackbourn, P., and Kirkley, J. (1972). British Fournal of Radiology, 45, 354.

Buckton, K. E., Smith, P. G., and Court Brown, W. M. (1967). In Human Radiation Cytogenetics, ed. H. J. Evans, W. M. Court Brown, and A. S. McLean, p. 106. Amsterdam, North Holland Publishing Company.

Campbell, S. (1968). Fournal of Obstetrics and Gynaecology of the British Commonwealth, 75, 568 .

Coakley, W. T., Slade, J. S., and Braeman, J. M. (1972). British fournal of Radiology, 45, 328 .

Donald, I. (1968) British Medical Bulletin, 24, 71 Donald, I., and Abdulla, U. (1968). Fournal of Obstetrics and Gynaecology

Evans, H. J. (1970). In Human Population Cytogenetics, ed. P. A. Jacobs, p. 191. Edinburgh, University Press.

Hill, C. R., Joshi, G. P., and Revell, S. H. (1972). British fournal of Radiology, 45, 333.

Macintosh, I. J. C., and Davey, D. A. (1970). British Medical fournal, 4, 92.

Macintosh, I.J.C. and Davey, D.A. (1972). British fournal of Radiology, 45, 320.

Serr, D. M., et al. (1970). Paper read at the European Congress of Perinatal Medicine, London.

United Nations Scientific Committee (1969). Report on Effects of Atomic

Radiation. New York, United Nations.
Watts, P. L., Hal, A. J., and Fleming, J. E. E. (1972). British fournal of Radiology, 45, 335 .

Willocks, J., Donald, I., Campbell, S., and Dunsmore, I. R. (1967)

Fournal of Obstetrics and Gynaecology of the British Commonwealth, 74, 639. 